\title{
Mathematicians Who Never Were
}

\section{Barbara Pieronkiewicz}

This column is a forum for discussion of mathematical communities throughout the world, and through all time. Our definition of "mathematical community" is the broadest: "schools" of mathematics, circles of correspondence, mathematical societies, student organizations, extra-curricular educational activities (math camps, math museums, math clubs), and more. What we say about the communities is just as unrestricted. We welcome contributions from mathematicians of all kinds and in all places, and also from scientists, historians, anthropologists, and others.

\section{Barbara Pieronkiewicz}

G H. Hardy and his close friend and long-time collaborator J. Littlewood are well known today. Most mathematicians of their time knew their names, too. However, since Littlewood had been seen in public places far less often than Hardy, some people joked about whether he really existed or not. Some even speculated openly that maybe Littlewood was only "a pseudonym that Hardy put on his weaker papers" (Krantz 2001, p. 47). Let's make it clear then: Littlewood was not just "a figment of Hardy's imagination" (Fitzgerald and James 2007, p. 136). He was real, unlike most of the famous scientists explored in this article.

\section{Nicolas Bourbaki}

The title of the "Most Famous Mathematician Who Never Existed" would probably go to Nicolas Bourbaki. In 1935 this name was chosen as a pen name by a group of young mathematicians educated at the École Normale Supérieure in Paris. The founders of the group were Henri Cartan, Claude Chevalley, Jean Coulomb, Jean Delsarte, Jean Dieudonné, Charles Ehresmann, René de Possel, Szolem Mandelbrojt, and André Weil. In 1952 they formed a group called Association des Collaborateurs de Nicolas Bourbaki. Through the years, the collective identity of Bourbaki has gathered numerous mathematicians, including Alexandre Grothendieck, Armand Borel, Gustave Choquet, and many others. All members were obliged to retire from the group at age fifty; thus, the cadre has changed over a span of time.

Indeed at least one real Bourbaki existed; a statue of the Napoleonic general Charles Bourbaki (1816-1897) stood in the town of Nancy, where some of the Bourbakists had worked (Clark 2005). The group probably came up with the idea of using his name after a lecture by an older student named Raoul Husson; some of the members had attended this lecture during their first year of studies. In this lecture Husson put on a false beard and introduced himself as a "distinguished venerable mathematician." He then went on to share a series of false theorems attributed to fictional mathematicians whose names were taken from French generals. Husson attributed his last theorem to "Bourbaki," which is where the surname came from (Weil 1992). And the name "Nicolas" was chosen by Eveline Possel, Weil's future wife. Some say it referred to the real general Bourbaki's ancient Greek ancestor, but others attribute the name to St. Nicolas, known for bringing gifts.

Indeed, there was a gift the group wanted to give to the scientific community. France had lost many mathematicians during World War I (1914-1918), and most of the lecturers of the 1930s were already ending their careers. There was a noticeable impasse and increasing uncertainty around the 
study of mathematics in France (Atiyah 2007). Young researchers took up the challenge of tackling the lack of clarity in definitions and rigor in proof.

The initial aim of the group was to write an analysis textbook that could supersede Goursat's Traité d'analyse (1915), but after they started working, their ideas became broader, eventually reaching into algebra and topology as well. In their famous treatise called Eléments de Mathématique (Elements of Mathematics) they aimed to provide a solid foundation for the whole body of modern mathematics. The title intentionally alluded to Euclid's Elements, and also intentional was the use of "Mathématique" instead of the more frequently used plural form, "Mathématiques." In Borel's words, that was "one way for Bourbaki to signal its belief in the unity of mathematics" (Borel 1998).

The Bourbakists' common objective was to reformulate the core areas of the mathematics of their time. Taking set theory as the cornerstone of their work, they wanted to proceed rigorously, formulating axioms as the basis from which they could derive elegant theorems and complete proofs. The new terminology introduced by Bourbaki changed the vocabulary used by pure mathematicians. Even to nonmathematicians, Bourbaki may be known for inventing the symbol of the empty set, creating terms such as injective, bijective, and surjective, which entered the school curriculum, and the dangerous bend-a symbol apparent in mathematical writings, indicating difficult passages to warn the reader against serious errors.

Nicolas Bourbaki had high aspirations. He requested membership in the American Mathematical Society two times $(1948,1950)$. At that time, the secretary of the AMS was J. R. Kline, who already knew the falsity of this fictional personage. Thus he rejected the Bourbaki's first membership request (Pitcher 1988). He expostulated his position clearly:

Now, really, these French are going too far. They have already given us a dozen independent proofs that Nicolas Bourbaki is a flesh and blood human being. He writes papers, sends telegrams, has birthdays, suffers from colds, sends greetings. And now they want us to take part in their canard. They want him to become a member of the American Mathematical Society (AMS). My answer is 'No' (Krantz 2011, p. 94).

The next request evoked a long and heated discussion among AMS authorities who did not agree unanimously. For example, past president of AMS Einar Hille opined:

I think a good case can be made out for granting membership. After all, a good fictitious character lives more intensely and a good deal longer than the humdrum reality. We know much more about Ulysses, who probably never existed, than about Thales who did. There is no question in my mind that $\mathrm{N}$. Bourbaki has made a strong impression on presentday mathematics and his fame will last longer than that of most present members of our Society (Pitcher 1988, pp. 160-161).
But in the end, AMS refused to grant Bourbaki an individual membership, and he never decided to apply for the institutional one.

Bourbaki again showed his sense of humor (some might say, a great deal of presumption too) when in the 1950s, Ralph Boas debunked his identity in an article written for the Encyclopaedia Britannica. Bourbaki immediately wrote to the editors to express outrage that anybody would call his existence into question. He also suggested that it was Ralph Boas himself who did not exist, and that B.O.A.S was nothing but an abbreviation for some American mathematicians' names (Mashaal 2006).

In 1968 the death of Bourbaki was announced, but the spirit of those times still keeps alive the group called $A s$ sociation des Collaborateurs de Nicolas Bourbaki.

The Bourbakists were perhaps the most prominent group among known groups of mathematicians who worked collectively under a fictitious name, but they were not the only ones. Other invented "collective-individual" mathematicians include:

D. P. Parent—created by D. Barsky, F. Bertrandias, G. Christol, A. Decomps, H. Delange, J. M. Deshouillers, K. Gerardin, J. Lagrange, J. L. Nicolas, M. Pathiaux, G. Rauzy, M. Waldschmidt, the author of Exercises in Number Theory (Parent 2013);

G. W. Peck-the initials of real authors writing under his name were: Ronald Graham, Douglas West, George B. Purdy, Paul Erdős, Fan Chung, and Daniel Kleitman;

John Rainwater-made up by Nick Massey and Sam Saunders; and

I. J. Schark-an acronym for real authors' given names: Irving Kaplansky, John Wermer, Shiuzo Kakutani, R. Creighton Buck, Halsey Royden, Andrew Gleason, Richard Arens, and Kenneth Hoffman (see Schark 1961).

\section{Ralph Boas, E. S. Pondiczery, and H. Pétard}

Ralph Boas (1912-1992), mentioned earlier, was himself an interesting character, although a real person. Boas received his A.B. degree in 1933 and then his Ph.D. in 1937 from Harvard University. The title of his dissertation (written under D. V. Widder) was "The Iterated Stieltjes Transform." Thanks to a National Research Fellowship, he spent two years in Princeton and Cambridge. Then he taught at Duke University (1939-1942), the U.S. Navy Pre-Flight School in Chapel Hill (1942-1943), Harvard University (1943-1945), and the Massachusetts Institute of Technology (1948-1949). He became a professor of mathematics at Northwestern University in 1950 and then chaired the department (19571972). He served as a member of the editorial boards of Mathematical Reviews (1945-1950), American Mathematical Monthly (1977-1980), and the Journal of Mathematical Analysis and Applications (1977-1981, 1985-1991). Boas was Vice President (1959-1960) and Trustee (1966-1970) of the American Mathematical Society, and President of the Mathematical Association of America (1973, 1974). In 1981 he received the Award for Distinguished Service to Mathematics from the Mathematical Association of America.

Boas, probably inspired by the Bourbaki hoax, together with Frank Smithies and with much support from John 
Tukey (Brillinger 2002), also created a fictional mathematician, a member of the Royal Institute of Poldavia. They called him Ersatz Stanislaus Pondiczery (Henriksen 1997) after Pondicheree, a city in India. The spelling was modified to make the name seem Slavic. The initials E. S. came from the idea of writing spoofs on extrasensory perception (E.S.P.) under this pseudonym (Halmos 1957). The paper was never submitted; nevertheless, the authors hoped that one day it would appear and they would sign it E.S.P., R.I.P. (the initials of the author and his affiliation). E. S. Pondiczery has reviewed many articles for the Mathematics Reviews but is probably best known for the Hewitt-Marczewski-Pondiczery theorem, independently dealt with by all the authors (Hewitt 1946, Marczewski 1947, Pondiczery 1944). Because of his fondness for pseudonyms, Boas also wrote under other names-for instance, Lemontré (lemon tree) or Zitronenbaum (Zorn 2015).

With his keen sense of humor, Boas not only played with names but also with mathematical ideas (Alexanderson and Mugler 1955, Boas, Alexanderson, and Mugler 1995). He knew how to extract a lot of joy from what he was doing, and his humorous articles, written in seemingly serious scientific style, have been eliciting cordial laughter for years. Perhaps the most famous paper of Boas is on the "little known mathematical discipline" called "Mathematical Theory of Big Game Hunting." Pondiczery submitted the paper to American Mathematical Monthly, and, by reason of the "obviously facetious nature of the material" (Halmos 1957), he asked the editors if they would let him publish the paper under the pseudonym H. Pétard (referring to Hamlet's line "hoist with his own petar").

Pétard (1938) wrote:

For the sake of simplicity of statement, we shall confine our attention to Lions (Felis leo) whose habitat is the Sahara Desert. The methods which we shall enumerate will easily be seen to be applicable, with obvious formal modifications, to other carnivores and to other portions of the globe. The paper is divided into three parts, which draw their material respectively from mathematics, theoretical physics, and experimental physics.

He did not forget the acknowledgments either:

The author desires to acknowledge his indebtedness to the Trivial Club of St. John's College, Cambridge, England; to the MIT chapter of the Society for Useless Research; to the F o P, of Princeton University; and to numerous individual contributors, known and unknown, conscious and unconscious.

Two famous mathematical methods for catching a lion were initially proposed by Pétard in this paper:

The method of inversive geometry:

We place a spherical cage in the desert, enter it and lock it from inside. We then perform an inversion with respect to the cage. Then the lion is inside the cage, and we are outside.

The Bolzano-Weierstrass method:

Divide the desert by a line running from N-S. The lion is then either in the $\mathrm{E}$ portion or in the $\mathrm{W}$ portion; let us assume him to be in the $\mathrm{W}$ portion. Bisect this portion by a line running from $\mathrm{E}-\mathrm{W}$. The lion is either in the $\mathrm{N}$ portion or in the $\mathrm{S}$ portion; let us assume him to be in the $\mathrm{N}$ portion. We continue this process indefinitely, constructing a sufficiently strong fence about the chosen portion at each step. The diameter of the chosen portions approaches zero, so that the lion is ultimately surrounded by a fence of arbitrarily small perimeter.

The interested reader will find many more methods in the article (Pétard 1938).

The question of how to catch a lion was revisited years later by I. J. Good (1965), who proposed a new method:

Let $Q$ be the operator that encloses a word in (single) quotation marks. Its square $Q^{2}$ encloses a word in double quotes. The operator clearly satisfies the law of indices, $Q^{m} Q^{n}=Q^{m+n}$. Write down the word lion, without quotation marks. Apply it to the operator $Q^{-1}$. Then a lion will appear on the page. It is advisable to enclose the page in a cage before applying the operator.

Two years later, Roselius (1967) summed up previous findings, noticing that what Pétard proved was that (a) "it is possible to capture a lion in the Sahara desert," and later (b) "it is possible to capture every lion with at most one exception." To fill the gap, he showed (Roselius 1967) that every lion may be captured. Mathematicians have been playing with the Big Game Hunting problem for many years (i.e., Morphy 1968, Dudley 1968, Barrington 1976, Euler 1985). Athreya and Khare wrote the latest paper I found (exact year unknown). The important remark they make, that "lions occur in groups-namely, Lieo groups," might shed some new light on the problem. Clearly the question remains of interest and clearly both E. S. Pondiczery and H. Pétard have left their marks in mathematics, without even existing.

\section{Family Connections}

It might surprise readers to learn that Pondiczery was indeed related by marriage to Bourbaki. According to the famous wedding announcement from 1939, Bourbaki's daughter named Betti was to marry Pondiczery's ward, Hector Pétard:

Monsieur Nicolas Bourbaki, Canonical Member of the Royal Academy of Poldavia, Grand Master of the Order of Compacts, Conserver of Uniforms, Lord Protector of Filters, and Madame nee One-to-One, have the honor of announcing the marriage of their daughter Betti with Monsieur Hector Pétard, Delegate Administrator of the Society of Induced Structures, Member of the Institute of Classified Archeologists, Secretary of the Work of the Lion Hunt.

Monsieur Ersatz Stanislas Pondiczery, retired First Class Covering Complex, President of the Reeducation Home for Weak Convergents, Chevalier of the Four U's, Grand Operator of the Hyperbolic Group, Knight of the Total Order of the Golden Mean, L.U.B., C.C., H.L.C., and Madame nee Compact-in-itself, have the honor of announcing the marriage of their ward Hector Pétard with Mademoiselle Betti Bourbaki, a former student of the Well-Ordereds of Besse. 
The trivial isomorphism will be given to them by $\mathrm{P}$. Adic, of the Diophantine Order, at the Principal Cohomology of the Universal Variety, the 3 Cartem-

ber, year VI, at the usual hour.

The announcement, of course, is filled with references to mathematics, expressed in the Bourbakists' style. Mathematical terms, such as "induced structures," "operator," and "golden mean," are used here outside of their original domain. Some of the hidden references are more sophisticated; for example, Bourbaki daughter's name came from Betti numbers, which are the topological objects proved by Poincaré to be invariants.

\section{Boo Barkee and F. D. C. Willard-Like a Dog and a Cat?}

The name of Boo Barkee, who lived in Ithaca, NY, is known for several papers he published alone (Barkee 1988) and with his colleagues (Barkee, Dennis, and Wang 1990, Barkee, Can, Ecks, Moriarty, and Ree 1994). As one can read in the work of Kreuzer and Robbiano (2005): "Boo Barkee revealed his love for mathematics when he licked a draft of the paper about SAGBI" (p. 477). According to Levy-dit-Vehel, Marinari, Perret, and Traverso (2009), some attribute legendary roots to Boo Barkee, stating that he was a French general of Greek origin (why do they hook onto French generals so much?). Have you already come to the conclusion that maybe Boo Barkee was a derivative form of Bourbaki? The truth is that Boo Barkee was a dog belonging to Moss Sweedler, who while writing his paper on cryptography decided to use his dog's name as a pseudonym.

At least two of Barkee's coauthors were using fake names too: Deh Cac Can was a pen name of D. Naccache, and Theo Moriarty was in fact Teo Mora. Julia Ecks and Richard Francis Ree have not disclosed their identities. Moss Sweedler, to whom Boo Barkee owes his scientific career, has been working within the fields of (among others) algebra and algebraic geometry, real-algebraic geometry, homological algebra, algebraic groups, simple algebras and generalizations of the Brauer group, and differential algebra. He is known for his classic book Hopf Algebras (Sweedler 1969). Together with Harry P. Allen, he provided a verification of Nathan Jacobson's conjectured classification of forms of the generalized Witt algebras over algebraically closed fields of finite characteristic (Allen and Sweedler 1969).

Perhaps Boo Barkee and F. D. C. Willard never met; yet they have a lot in common. Willard published in physics and his first coauthorship dates back to 1975 , when the paper he had written together with Hetherington was published in Physical Review Letters. Actually Hetherington wrote the paper all by himself, but was told that the editors would not accept the plural first-person pronouns (which he used) in a paper having one author only. He did not want to revise and retype the whole article, so he decided to solve the problem by adding a coauthor. He created a fictional professor from Michigan University, whose prototype was his own cat. The coauthor's name then, could not be other than F. D. C. Willard, where F. D. stood for felix domesticus, C for Chester-the cat's real name, and Willard for the cat's father's name (Nickon and Silversmith 2013). Willard published only one further paper (Willard 1980) and ended his career.

\section{Shalosh B. Ekhad}

Since the late 1980s, Doron Zeilberger, a mathematician at Rutgers University, has published several papers coauthored by Shalosh B. Ekhad, which is the name he gave to his computer. The Hebrew human-sounding name refers to AT\&T 3B1 (Shalosh means three and Ekhad-one), a workstation computer owned by Zeilberger long time ago. Nowadays a growing number of mathematicians use computers very often in their daily work to test hypotheses, seek patterns, discover conjectures, and generate computer-assisted proofs. Zeilberger acknowledges the impact that computers have on the development of mathematics today. He decided to make the computer a coauthor of his articles because he believes that "computers should get credit where credit is due."

\section{Concluding Questions}

Fiction writers and movie producers often create imaginary mathematicians who end up being stereotypical and caricaturish. Here we explored some fictitious mathematicians-and one exceptional physicist—who were fabricated by active researchers in the field. If we choose to approach these figments of imagination as mathematologists who "specialize in the study of mathematicians and their peculiarities" (Albers and Alexanderson 2011), what do we see? What can we learn about mathematicians from these examples of fictitious scientists, conceived and born within the scientific community?

Note: The author hereby declares that she does exist and she is neither a cat, nor a dog, nor any other four-legged animal.

Institute of Mathematics

Pedagogical University of Cracow

ul. Podchorążych 2, 30-084

Cracow

Poland

e-mail: barbara.pieronkiewicz@up.krakow.pl

\section{OPEN ACCESS}

This article is distributed under the terms of the Creative Commons Attribution 4.0 International License (http:// creativecommons.org/licenses/by/4.0/), which permits unrestricted use, distribution, and reproduction in any medium, provided you give appropriate credit to the ori ginal author(s) and the source, provide a link to the Creative Commons license, and indicate if changes were made.

\section{REFERENCES}

Alexanderson, Gerald L.; Mugler, Dale H.: Lion-Hunting \& Other Mathematical Pursuits, Mathematical Association of America, Washington, DC, 1955. 
Atiyah, Michael: Commentary-Bourbaki, A Secret Society of Mathematicians and the Artist and the Mathematician-A Book Review, Notices of the American Mathematical Society, 2007, 54(9): 1150-1152.

Athreya, J.; Khare, A.: Big Game Hunting for Graduate Students in Mathematics. Retrieved from Jan 23, 2016, https://pdfs.seman ticscholar.org/72ed/ce2a49061498f02fdc6006648162c6d8f3cb.pdf.

Barkee, Boo: Groebner Bases: The Ancient Secret Mystic Power of the ALGU Compubraicus: A Revelation Whose Simplicity Will Make Ladies Swoon and Grown Men Cry, Mathematical Sciences Institute, Cornell University, 1988.

Barkee, Boo; Dennis, R. Keith; Wang, Stuart Sui-Sheng: Automorphisms Are Determined by Their Face Polynomials, Archiv der Mathematik, 1990, 55(5): 429-430.

Barkee, B.; Can, D. C.; Ecks, J.; Moriarty, T.; Ree, R. F.: Why You Cannot Even Hope to Use Gröbner Bases in Public Key Cryptography: An Open Letter to a Scientist Who Failed and a Challenge to Those Who Have Not Yet Failed, Journal of Symbolic Computation, 1994, 18(6): 497-501.

Barrington, John: 15 New Ways to Catch a Lion, The Best of Manifold, 1968, 1980.

Boas, Ralph P.; Alexanderson, Gerald L.; Mugler, Dale H.: Lion Hunting and Other Mathematical Pursuits: A Collection of Mathematics, Verse, and Stories by the Late Ralph P. Boas, Jr., Cambridge University Press, 1995.

Borel, Armand: Twenty-five years with Nicolas Bourbaki, 1949-1973, Notices of the AMS, 1998, 45(3): 373-380.

Brillinger, David R.: John W. Tukey's work on time series and spectrum analysis. Annals of Statistics, 2002, 1595-1618.

Clark, Claudia: The Author Who Never Was: Nicolas Bourbaki, Science, 2005, 28(3): 83.

Dudley, P. L.; Evans, G. T.; Hansen, K. D.; Richardson, I. D.: Further Techniques in the Theory of Big Game Hunting, American Mathematical Monthly, 1968, 896-897.

Euler, Houston: Lion-Hunting with Logic, American Mathematical Monthly, 1985, 140-140.

Fitzgerald, Michael; James, loan: The Mind of the Mathematician. The Australian Mathematical Society, 2007, 271.

Good, I. J.: A New Method of Catching a Lion, American Mathematical Monthly, 1965, 72, 436.

Goursat, Édouard: Traité d'analyse, Gauthier Villars, Paris, 1915, 2.

Halmos, Paul R.: "Nicolas Bourbaki," Scientific American, 1957, 196: 88-89.
Henriksen, Melvin: Pondiczery was Ralph Boas. A Historical Vignette, http://at.yorku.ca/t/o/p/c/40.htm.

Hetherington, J. H.; Willard, F. D. C.: Two-, Three-, and Four-Atom Exchange Effects in bcc He 3, Physical Review Letters, 1975, 35(21): 1442.

Hewitt, Edwin: A Remark on Density Characters, Bulletin of the American Mathematical Society, 1946, 52(8): 641-643.

Krantz, Steven G.: Mathematical Anecdotes. In: Mathematical Conversations, Springer New York, 2001, pp. 39-48.

Krantz, Steven G.: The Proof Is in the Pudding: The Changing Nature of Mathematical Proof, Springer Science+Business Media, 2011.

Kreuzer, Martin; Robbiano, Lorenzo: Computational Commutative Algebra 2, Springer Science+Business Media, 2005.

Levy-Dit-Vehel, F.; Marinari, M. G.; Perret, L.; Traverso, C.: A Survey on Polly Cracker Systems. In: Gröbner Bases, Coding, and Cryptography. Springer Berlin Heidelberg, 2009, pp. 285-305.

Marczewski, Edward: Séparabilité et multiplication cartésienne des espaces topologiques. Fundamenta Mathematicae, 1947, 1(34): 127-143.

Mashaal, Maurice: Bourbaki: A Secret Society of Mathematics, American Mathematical Society, 2006.

Morphy, Otto: Some Modern Mathematical Methods in the Theory of Lion Hunting, American Mathematical Monthly, 1968, 185-187.

Nickon, Alex; Silversmith, Ernest F.: Organic Chemistry: The Name Game: Modern Coined Terms and Their Origins, Elsevier, 2013.

Parent, D. P.: Exercises in Number Theory, Springer Science+Business Media, 2013.

Pétard H.: A Contribution to the Mathematical Theory of Big Game Hunting, American Mathematical Monthly, 1938, 45, 446-447.

Pitcher, Everett: A History of the Second Fifty Years: American Mathematical Society, 1939-1988, American Mathematical Society, 1988.

Pondiczery, E. S., et al.: Power problems in abstract spaces. Duke Mathematical Journal, 1944, 11(4): 835-837.

Roselius, Christian: On a Theorem of H. Pétard. American Mathematical Monthly, 1967, 838-839.

Weil, André: The Apprenticeship of a Mathematician, Springer Science+Business Media, 1992.

Willard, F. D. C.: Solid He-3, A Nuclear Anti-Ferromagnetic, Recherche, 1980, 11(114): 972-973.

Zorn, Paul: A Century of Advancing Mathematics, The Mathematical Association of America, 2015. 